\title{
Risk factors for female and male homicidal strangulation in Johannesburg, South Africa
}

\author{
S Suffla, DPhil; M Seedat, DPhil \\ Institute for Social and Health Sciences, University of South Africa; and South African Medical Research Council-University of South Africa \\ Masculinity and Health Research Unit, Cape Town, South Africa
}

Corresponding author: S Suffla (ssuffla@mrc.ac.za)

Background. There is a paucity of research on homicidal strangulation by gender.

Objectives. A sex-disaggregated and comparative research approach was used to investigate individual-level risk factors for female and male homicidal strangulation in Johannesburg, South Africa (2001 - 2010).

Methods. Data were drawn from the National Injury Mortality Surveillance System. Logistic regressions were used to examine associations between each of the independent variables and homicidal strangulation in females and males relative to all other female and male homicides, respectively.

Results. The risk of fatal strangulation was high for both females and males aged $\geq 60$ years, but markedly high only for male children and adolescents. Temporal risk for females was undifferentiated for day of the week, and the risk for males was high during weekdays. Females were more likely to be strangled in public places, and males in private locations.

Conclusions. The study underlines the importance of disaggregating homicide by external cause and gender.

S Afr Med J 2020;110(8):802-806. https://doi.org/10.7196/SAMJ.2020.v110i8.14412

Gender-focused research is integral to homicide research that disaggregates fatal events into finer conceptual categories to explain the individual, situational and structural factors that present as unique across homicide causes and types. The gendering of homicide research is specifically supported by the argument that the inclusion of gender in analyses on lethal violence strengthens theoretical explanations through rejecting erroneous assumptions about similarities between females and males. ${ }^{[1]}$ The inclusion of a gender focus in homicide analyses also develops the potential depth and rigour associated with conducting comparative research, especially as it helps to uncover factors assumed to be universal in explaining female and male homicide occurrence, ${ }^{[2]}$ and to inform the development of gender-sensitive prevention interventions. Sexspecific homicide analyses therefore highlight the distinguishing nature of gender and gender experiences, and the ways in which this distinctiveness contextualises and explains, as well as informs, lethal violence.

Sex-specific homicide studies have focused on female and male homicide individual-level victimisation patterns of occurrence within and between cities and countries, ${ }^{[3-5]}$ as well as the association of female and male homicide with a range of sociostructural factors. ${ }^{[6-9]}$ However, disaggregated studies on strangulation homicide risk and gender are rare. The small body of research on homicidal strangulation has provided descriptive and forensic accounts, including the identification of lethal strangulation risk profiles ${ }^{[10]}$ and non-fatal strangulation as a risk factor for attempted and completed homicide of women. ${ }^{[11-13]}$

\section{Objectives}

Building on the authors' descriptive analysis ${ }^{[10]}$ and the assessment of sociodemographic and spatiotemporal predictors of homicidal strangulation for females and males combined, ${ }^{[3]}$ this study employed a sex-disaggregated and comparative research approach to investigate the individual-level risk factors for female and male homicidal strangulation in Johannesburg, South Africa (SA) (2001 - 2010). The study focused on individual-level risk factors that differentiate female homicidal strangulation from other female homicides, and the individual-level risk factors that differentiate male homicidal strangulation from other male homicides.

\section{Methods}

\section{Data}

Data on all the valid homicidal strangulation cases recorded for Johannesburg (2001 - 2010) were drawn from the National Injury Mortality Surveillance System (NIMSS). The NIMSS, a mortuary surveillance system and a source of secondary data, provides information about deaths from external causes, collated from investigative procedures at forensic pathology and chemistry laboratories. Data included information on mechanism of homicide; sociodemographic profile of each strangulation victim (age, race and sex); and spatial and temporal descriptions of each case (time, day and month of the victim's death, and scene of homicidal injury). Information on the victim's blood alcohol concentration (BAC) was not included in the current analyses owing to the high proportion of missing data.

\section{Dependent variable}

Female and male homicidal strangulation were coded separately as the dependent variable for the two analyses undertaken in this study. All other homicides recorded for Johannesburg for the specified period served as the reference category. Of the total of 9920 cases recorded, homicidal strangulation accounted for $2.2 \% \quad(n=218)$ of all deaths, representing the smallest proportion of all deaths relative to firearm discharge, sharp-object homicide and blunt-object homicide ${ }^{[3]}$ Males represented a disproportionately high percentage of victims for all homicides combined (86.5\%; $n=8580)$, with $1 \%$ of 
deaths ( $n=88$ ) occurring from strangulation, and females constituted $13.5 \%(n=1340)$ of all victims, with $9.7 \%$ of deaths $(n=130)$ attributed to strangulation. The strangulation homicide dataset excluded 116 cases (34.7\%) with missing data.

\section{Independent variables}

The independent variables comprised sociodemographic and spatiotemporal predictors. These predictors account for variations in homicide risk across different contexts and groups. ${ }^{[3]}$ The sociodemographic predictors included two independent variables: (i) age group: 0 - 14, $15-29,30-44,45-59$ and $\geq 60$ years of age, with the latter coded as the reference category; and (ii) race: Indian, coloured, white and black, with the latter coded as the reference category. The authors note that in SA, the terms Indian, black, coloured (referring to mixed heritage) and white are an artefact of the apartheid period. Their use is contentious and does not imply acceptance of the racist assumptions on which these labels were founded. The spatiotemporal predictors incorporated four variables: (i) time of day: day (05h00 - 18h59) and night (19h00 - 04h49), with night coded as the reference category; (ii) day of the week: weekdays and weekend (commencing on Friday at 16h00), with the latter representing the reference category; (iii) month of death by seasonal cycle, with spring coded as the reference category; and (iv) scene of death: private and public places, with the latter serving as the reference group.

Cases with missing values were excluded. Given the smaller number of cases for which BAC data were available (40.9\%) and the substantially reduced sample size that the inclusion of BAC data would have implied, BAC was not included as an independent variable. The analysis of missing values indicated that BAC was 'missing not at random', signifying a non-representative sample and biased estimates, while all the other variables were 'missing at random?

Table 1 presents the frequency distribution of all the variables included in the analyses, aggregated for female and male homicide, respectively. The majority of female victims were distributed across the 15 - 29-year $(37.8 \% ; n=507)$ and $30-44$-year $(37.5 \% ; n=503)$ age ranges. A preponderance of male deaths was recorded in these same age categories, $42.2 \%(n=3621)$ and $41.2 \%(n=3537)$, respectively. Black male $(88.3 \% ; n=7578)$ and female $(81.5 \% ; n=1$ 092) deaths accounted for the largest proportion of all deaths in females and males alike. Whereas fewer males were murdered during the day than at night time (43.2\%; $n=3709)$, more female homicides occurred during the day $(56.3 \% ; n=755)$. There were fewer male fatalities during the week ( $48.4 \% ; n=4153)$ than over the weekend, compared with female victims, for whom the inverse was noted $(56.3 \%$; $n=55)$. Homicides were almost equally distributed across the seasons of the year, with a slightly greater clustering around winter and spring for both females and males. Private places were the scene of injury for the majority of female and male deaths, and there was a larger proportion of deaths of women in private places $(73.1 \% ; n=980)$ compared with public places $(26.9 \% ; n=360)$.

\section{Logistic regression analyses}

Logistic regressions were conducted separately, examining the independent associations between each of the predictor variables and homicidal strangulation in females and males in relation to all other female and male homicides, respectively. All other female homicides combined and all other male homicides combined were coded as the reference categories. Theoretically similar predictor variables were added sequentially to the analyses. The logistic regression analyses assessed the risks associated with female and male homicidal

\begin{tabular}{|c|c|c|}
\hline & $\begin{array}{l}\text { Females }(N=1340), \\
n(\%)\end{array}$ & $\begin{array}{l}\text { Males }(N=8580), \\
n(\%)\end{array}$ \\
\hline \multicolumn{3}{|c|}{ Homicide mechanism } \\
\hline Strangulation & $130(9.7)$ & $88(1)$ \\
\hline Other & $1210(90.3)$ & 8492 (99) \\
\hline \multicolumn{3}{|l|}{ Age (years) } \\
\hline $0-14$ & $65(4.9)$ & $108(1.3)$ \\
\hline $15-29$ & $507(37.8)$ & $3621(42.2)$ \\
\hline $30-44$ & $503(37.5)$ & $3537(41.2)$ \\
\hline $45-59$ & $182(13.6)$ & $1016(11.8)$ \\
\hline$\geq 60$ & $83(6.2)$ & $298(3.5)$ \\
\hline \multicolumn{3}{|l|}{ Race } \\
\hline Indian & $25(1.9)$ & $163(1.9)$ \\
\hline Coloured & $62(4.6)$ & $303(3.5)$ \\
\hline White & $161(12)$ & $536(6.2)$ \\
\hline Black & $1092(81.5)$ & $7578(88.3)$ \\
\hline \multicolumn{3}{|l|}{ Time of day } \\
\hline Day & $736(54.9)$ & $3709(43.2)$ \\
\hline Night & $604(45.1)$ & $4871(56.8)$ \\
\hline \multicolumn{3}{|l|}{ Day of week } \\
\hline Weekday & $755(56.3)$ & $4153(48.4)$ \\
\hline Weekend & $585(43.7)$ & $4427(51.6)$ \\
\hline \multicolumn{3}{|l|}{ Season of year } \\
\hline Summer & $316(23.6)$ & $2086(24.3)$ \\
\hline Autumn & $326(24.3)$ & $2000(23.3)$ \\
\hline Winter & $368(27.5)$ & $2256(26.3)$ \\
\hline Spring & $330(24.6)$ & $2238(26.1)$ \\
\hline \multicolumn{3}{|l|}{ Scene of injury } \\
\hline Private & $980(73.1)$ & $4431(51.6)$ \\
\hline Public & $360(26.9)$ & $4149(48.4)$ \\
\hline
\end{tabular}

strangulation, respectively, each analysis examining a different model. The first model examined sociodemographic factors only, and the second model included spatial and temporal variables. Model coefficients were exponentiated so that they could be translated into adjusted odds ratios (ORs), and 95\% confidence intervals (CIs) were calculated to measure the magnitude and significance of adjusted multivariate associations. A $p$-value $<0.05$ was considered significant. Statistical analyses were performed using the Statistical Package for the Social Sciences (SPSS), version 22 (IBM, USA).

\section{Ethical considerations}

Ethical approval for the study was granted by the University of South Africa's Department of Psychology Human Research Ethics Committee (ref. no. 12-11-2014).

\section{Results}

\section{Female strangulation homicide v. all other female} homicides

\section{Model 1}

The overall model when compared with the constant-only model tested significant at the $p<0.05$ level $\left(\chi^{2}=39.485, p=0.000\right.$ with degrees of freedom $(\mathrm{df})=7)$. At the multivariate level, age was a significant predictor of female homicidal strangulation. When compared with the $\geq 60$-year age group, females in the 15 - 29, 30 - 44 and 45 - 49-year age categories were respectively 2.62 (OR $0.381 ; 95 \%$ CI $0.193-0.751$; $p<0.05$ ), 3.55 (OR 0.282; 95\% CI $0.143-0.554 ; p<0.05$ ) and 3.88 


\begin{tabular}{|c|c|c|c|c|c|c|c|c|}
\hline \multirow[b]{3}{*}{ Independent variable } & \multicolumn{4}{|c|}{ Females $^{\dagger}$} & \multicolumn{4}{|c|}{ Males ${ }^{*}$} \\
\hline & \multicolumn{2}{|c|}{ Model 1} & \multicolumn{2}{|c|}{ Model 2} & \multicolumn{2}{|c|}{ Model 1} & \multicolumn{2}{|c|}{ Model 2} \\
\hline & OR & $95 \% \mathrm{CI}$ & OR & $95 \% \mathrm{CI}$ & OR & $95 \% \mathrm{CI}$ & OR & $95 \% \mathrm{CI}$ \\
\hline \multicolumn{9}{|l|}{ Sociodemographic } \\
\hline \multicolumn{9}{|l|}{ Age (years) } \\
\hline $0-14$ & 1.051 & $0.457-2.420$ & 0.999 & $0.426-2.342$ & $4.130^{*}$ & $1.855-9.194$ & $4.376^{*}$ & $1.914-10.006$ \\
\hline $15-29$ & $0.381^{*}$ & $0.193-0.751$ & $0.375^{\star}$ & $0.187-0.750$ & $0.138^{*}$ & $0.066-0.287$ & $0.194^{*}$ & $0.092-0.411$ \\
\hline $30-44$ & $0.282^{*}$ & $0.143-0.554$ & $0.274^{*}$ & $0.137-0.549$ & $0.143^{*}$ & $0.070-0.290$ & $0.186^{*}$ & $0.090-0.384$ \\
\hline $45-59$ & $0.258^{*}$ & $0.118-0.563$ & $0.264^{*}$ & $0.120-0.579$ & $0.192^{*}$ & $0.086-0.429$ & $0.222^{*}$ & $0.098-0.501$ \\
\hline$\geq 60$ & Ref. & Ref. & Ref. & Ref. & Ref. & Ref. & Ref. & Ref. \\
\hline \multicolumn{9}{|l|}{ Race } \\
\hline Indian & 2.654 & $0.943-7.469$ & 2.575 & $0.903-7.342$ & $2.990^{*}$ & $1.042-8.582$ & 2.807 & $0.979-8.052$ \\
\hline Coloured & $2.527^{\star}$ & $1.255-5.089$ & $2.559^{*}$ & $1.254-5.222$ & 1.424 & $0.500-4.055$ & 1.346 & $0.459-3.947$ \\
\hline White & 1.496 & $0.850-2.665$ & 1.457 & $0.809-2.621$ & $2.422^{*}$ & $1.275-4.601$ & $2.191^{\star}$ & $1.138-4.219$ \\
\hline Black & Ref. & Ref. & Ref. & Ref. & Ref. & Ref. & Ref. & Ref. \\
\hline \multicolumn{9}{|l|}{ Spatiotemporal } \\
\hline \multicolumn{9}{|l|}{ Time of day } \\
\hline Day & - & - & $1.715^{\star}$ & $1.141-2.576$ & - & - & $3.133^{\star}$ & $1.902-5.159$ \\
\hline Night & - & - & Ref. & Ref. & - & - & Ref. & Ref. \\
\hline \multicolumn{9}{|l|}{ Day of week } \\
\hline Weekday & - & - & 1.113 & $0.752-1.645$ & - & - & $1.942^{*}$ & $1.199-3.148$ \\
\hline Weekend & - & - & Ref. & Ref. & - & - & Ref. & Ref. \\
\hline \multicolumn{9}{|l|}{ Season of year } \\
\hline Summer & - & - & $2.336^{*}$ & $1.297-4.206$ & - & - & 1.723 & $0.874-3.400$ \\
\hline Autumn & - & - & $2.087^{\star}$ & $1.152-3.780$ & - & - & $2.040^{*}$ & $1.047-3.973$ \\
\hline Winter & - & - & $1.846^{*}$ & $1.023-3.332$ & - & - & 1.565 & $0.791-3.098$ \\
\hline Spring & - & - & Ref. & Ref. & - & - & Ref. & Ref. \\
\hline \multicolumn{9}{|l|}{ Scene of injury } \\
\hline Private & - & - & $0.593^{*}$ & $0.399-0.881$ & - & - & $2.066^{*}$ & $1.292-3.305$ \\
\hline Public & - & - & Ref. & Ref. & - & - & Ref. & Ref. \\
\hline Likelihood ratio tests & \multicolumn{2}{|c|}{$\begin{array}{l}\text { Model } \chi^{2}=39.485 \\
p=0.000\end{array}$} & \multicolumn{2}{|c|}{$\begin{array}{l}\text { Model } \chi^{2}=65.989 \\
p=0.000\end{array}$} & \multicolumn{2}{|c|}{$\begin{array}{l}\text { Model } \chi^{2}=120.250 \\
p=0.000\end{array}$} & \multicolumn{2}{|c|}{$\begin{array}{l}\text { Model } \chi^{2}=167.485 \\
p=0.000\end{array}$} \\
\hline $\begin{array}{l}\text { Pseudo R-square (females } \\
n=1340 \text {, males } n=8580 \text { ) }\end{array}$ & \multicolumn{2}{|c|}{ Nagelkerke $=0.062$} & \multicolumn{2}{|c|}{ Nagelkerke $=0.102$} & \multicolumn{2}{|c|}{ Nagelkerke $=0.129$} & \multicolumn{2}{|c|}{ Nagelkerke $=0.179$} \\
\hline $\begin{array}{l}\text { OR = odds ratio; } \mathrm{CI}=\text { confidence in } \\
{ }^{*} p<0.05 \text {. } \\
{ }^{*} \text { The reference category for the depe } \\
{ }^{*} \text { The reference category for the depe } \\
\text { The blank cells reflect the modelling }\end{array}$ & $\begin{array}{l}\text { rval; Ref. = } \\
\text { lent variab } \\
\text { lent variab }\end{array}$ & $\begin{array}{l}\text { erence category. } \\
\text { 'All other female } \\
\text { 'All other male ho }\end{array}$ & $\begin{array}{l}\text { ides'. } \\
\text { les.' }\end{array}$ & & & & & \\
\hline
\end{tabular}

(OR 0.258; 95\% CI $0.118-0.563$; $p<0.05$ ) times less likely to be murdered by strangulation relative to all other female homicides. Although the aggregate effect for age was found to be significant, the decomposed effects demonstrated a non-significant result for the youngest age group ( 0 - 14 years). Compared with black females, coloured females were 2.5 times more likely to die from strangulation (OR 2.527; 95\% CI $1.244-5.089 ; p<0.05$ ) as opposed to all other female homicides. The decomposed effects were not significant for Indians and whites when compared with blacks.

\section{Model 2}

The overall model was significant $\left(\chi^{2}=65.989, p=0.000\right.$ with $\left.\mathrm{df}=13\right)$ at the $p<0.05$ level. After controlling for all the variables in the analysis, age and race were significant predictors of female fatal strangulation. The direction of the relationship between each of these two independent variables and the dependent variable, as well as their decomposed effects, were identical to the results observed for model 1 . Women aged $\geq 60$ years and coloured females, compared with black females, were most at risk of fatal strangulation relative to all other female homicides. Time of day significantly predicted female homicidal strangulation in relation to all other female homicides. Compared with night-time strangulations, the risk of being strangled to death during the day was almost 2 times higher (OR 1.715; 95\% CI 1.141 - 2.576; $p<0.05)$. Compared with spring, females were $\sim 2.5$ times more likely to be strangled in summer (OR 2.336; $95 \%$ CI 1.297 - 4.206; $p<0.05$ ), slightly less than in autumn (OR 2.087; 95\% CI 1.152 - 3.780; $p<0.05$ ) and winter (OR 1.846; 95\% CI 1.023 - 3.332; $p<0.05)$. Scene of death was found to predict female strangulation homicide: females were 1.67 times less likely to die in private places (OR 0.593; 95\% CI $0.399-0.881 ; p<0.05$ ) than in public locations relative to all other female homicides.

\section{Male strangulation homicide v. all other male homicides} Model 1

Results indicated the overall logistic regression model to be statistically significant at the $p<0.05$ level $\left(\chi^{2}=120.250, p=0.000\right.$ with 
$\mathrm{df}=7$ ). The estimated effects for age were similar to those reported for females. When compared with the $\geq 60$-year age group, males aged 15 - 29, 30 - 44 and 45 - 49 years were respectively 7.25 (OR 0.138; 95\% CI 0.066 - 0.287; $p<0.05$ ), 7 (OR 0.143; 95\% CI 0.070 - 0.290; $p<0.05)$ and $5.2(\mathrm{OR} 0.192 ; 95 \%$ CI $0.086-0.429 ; p<0.05)$ times less likely to be fatally strangled relative to all other male homicides. Risk estimates were lower than those reported for females in the same age categories relative to all other female homicides. Unlike the nonsignificant effect reported for child and adolescent females, males aged 0 - 14 were $\sim 4$ times (OR 4.130; 95\% CI 1.855 - 9.194; $p<0.05$ ) more likely to be strangled to death compared with the $\geq 60$-year group relative to all other male homicides. The decomposed effects for race indicate that in comparison with blacks, Indian males were almost 3 times more at risk for fatal strangulation (OR 2.990; 95\% CI $1.042-8.582 ; p<0.05$ ) and whites 2.5 times more at risk (OR 2.422; $95 \%$ CI 1.275 - 4.601; $p<0.05$ ) in relation to all other male homicides. The effect for coloured males was non-significant, in contrast to female strangulation homicides.

\section{Model 2}

The overall logistic regression model was statistically significant at the $p<0.05$ level $\left(\chi^{2}=167.485, p=0.000\right.$ with $\left.\mathrm{df}=13\right)$. The nature and direction of the relationships between age and the dependent variable were almost identical to model 1 . Relative to all other male homicides, the effect estimates indicated a pronounced increase in risk for the 0 - 14-year age group (OR 4.376; 95\% CI 1.914 - 10.006; $p<0.05$ ) in comparison with the $\geq 60$-year age category. Although the aggregate effect of race was non-significant, the decomposed effects indicated that compared with blacks, white males were at $\sim 2$ times higher risk (OR 2.191; 95\% CI $1.138-4.219 ; p<0.05$ ) of fatal strangulation in relation to all other male homicides. The effect for Indians approached significance $(p=0.055)$. The localised effects were non-significant for coloured males. The probability of being fatally strangled during the day, as opposed to at night, was $>3$ times higher (OR 3.133; $95 \%$ CI $1.902-5.159 ; p<0.05)$ relative to all other male homicides. Disaggregated by sex and relative to all other male and female homicides, respectively, the risk of daytime strangulation was higher in males than in females. The predictive effects for day of week were also significant, with males almost 2 times as likely (OR 1.942; 95\% CI 1.199 - 3.148; $p<0.05)$ to be strangled during the week than over the weekend in relation to all other male homicides. While the overall effect of seasonality was non-significant, the decomposed results showed autumn to be a significant predictor of male strangulations. In comparison with spring, the risk of strangulation death in autumn was 2 times higher (OR 2.040; 95\% CI $1.047-3.973 ; p<0.05$ ) in relation to all other male homicides. In contrast to the female strangulation risk patterns, the $\mathrm{B}$ coefficient's positive direction indicated that males were 2 times more likely (OR 2.066; 95\% CI $1.292-3.305 ; p<0.05$ ) to be strangled to death in private locations than in public places.

\section{Discussion}

The results indicate differential fatal strangulation risks for females and males. The risk of fatal strangulation was distinctly higher for both females and males aged $\geq 60$ years, contrary to indications showing overall homicide risk to be concentrated among younger males. ${ }^{[14]}$ Referencing studies indicating that older victims of violent crime are likely to be assaulted by strangers and victimised in their own homes, ${ }^{[15,16]}$ it is speculated that the elderly are being strangled in the commission of other serious crimes, such as house robbery.

Disaggregated by sex, the risk for male child and adolescent fatal strangulation is high, corresponding with estimates that register the overall male child homicide rate to be nearly twice the female rate $(6.9 / 100000) .{ }^{[17]}$ While younger children are very physically vulnerable to strangulation attack, the incongruent risk effects for boys and girls suggest the need to consider the higher vulnerability among adolescent males alongside their excess mortality $\left(27.1 / 100\right.$ 000). ${ }^{[17]}$ It is likely that males in this age group are beginning to be involved in contests for power, domination and influence, and in inter-gender conflicts, yet remain vulnerable to the violence associated with hegemonic masculinities. This explanation finds support in the typology for adolescent homicide victimisation in urban SA, which reports the majority of adolescent homicides to be all-male victimoffender encounters. ${ }^{[18]}$

Coloured females were at significantly higher risk of being strangled to death in the within-sex analyses, and white males when the stronger within-sex model (model 2) is considered, mirroring race-specific rates reported elsewhere. ${ }^{[10]}$ Previous research shows coloured women to have the highest rates of female strangulation homicide ${ }^{[19]}$ and intimate femicide. ${ }^{[20]}$ Despite the absence of data on victim-perpetrator relationships, it is suggested that coloured women may be the target of expressive strangulation homicide perpetrated by males in social and relationship contexts of heightened aggression and hostility. ${ }^{[21]}$ With regard to the effects for Indian and white males, the finding may be revealing of the lower risk of strangulation for males from the other two race groups. Alternatively, in the case of white men, the higher probability of strangulation death may be linked to the observed age effects. This group of males may be represented largely by elderly white men being strangled in the context of instrumental homicide, or homicide motivated by gain.

Whereas daytime is shown to be a period of higher risk in the sexdisaggregated analyses, the effects for day of the week emerge as nonsignificant for females, diverging from research revealing risk to be higher at night and over weekends. ${ }^{[4,22,23]}$ The inverse time of day and day of week pattern noted here may be reflective of the opportunistic or predatory nature of strangulation homicide. The day-of-week effects for females suggest that the risk of strangulation violence is even across the days of the week. Although statistically significant, the predictive effects for seasonality did not exhibit a conceptually coherent risk profile. Seasonal patterns in interpersonal violence usually account minimally for variances in crime rates and risks. ${ }^{[2]}$

Although relatively marginal in effect, females were less likely to be strangled in private locations, with the direction of predictive effects being the opposite for males. Prior research ${ }^{[10,18,25]}$ shows the reverse pattern. The current findings support the argument that females may be vulnerable away from home because they are more accessible targets to strangers. ${ }^{[26]}$ The findings for males may be reflective of interaction with age and temporal effects, pointing to fatal strangulation risk in the commission of instrumental crime. In the aggregate, female homicide is explained as resulting from violence by male intimate partners perpetrated within the home, whereas for men fatal violence is considered to be largely concentrated in public spaces. ${ }^{[27]}$ However, it is likely that homicide risk profiles have become more diverse over time, revealing unique and emergent risk characteristics, which increasingly appears to be the case for homicide by strangulation.

\section{Study limitations}

Owing to missing and incomplete data, a high percentage of cases and BAC data were excluded from the analyses, with disaggregation contributing to a smaller number of observations for the logistic regressions. Although the most inclusive source of homicide data for the Johannesburg area, the NIMSS does not register perpetrator 
information, thereby restricting analysis of risks associated with the victim-perpetrator relationship. The exclusion of sociostructural variables did not permit examinations of potential interacting influences of the individual and the social on strangulation. The multivariate analyses were employed principally to determine probabilities rather than causation; the brief explanations of fatal strangulation risk by gender are therefore to be read as speculative.

\section{Conclusions}

Notwithstanding the limitations, the study provides evidence on the gender gradient in homicidal strangulation risk and underlines the importance of undertaking a sex-disaggregated and comparative approach to homicide research. Follow-up studies using current data and larger case samples will clarify the patterns suggested in the current study, and raise the public policy and research salience of analyses of fatal strangulation. Prevention programmes that are sensitive to gender and age, and include the strengthening of social protection systems, are critical for reducing strangulation risk and homicide. Furthermore, screening for the physical and psychological manifestations of strangulation in healthcare settings is indicated for the recognition, management and prevention of fatal strangulation risk. Such screening requires the training of health professionals and the development of lethality risk assessment tools to identify fatal strangulation risk.

Declaration. The research for this study was done in partial fulfilment of the requirements for SS's DPhil degree at the University of South Africa.

Acknowledgements. The authors thank the NIMSS project team and forensic pathology facilities for the registration and management of the data that this study draws from.

Author contributions. SS contributed to the study conceptualisation, design, data analysis and interpretation, and drafting of the article. MS contributed to the conceptualisation and design of the study, and revision of the article for intellectual content. Both authors read and approved the final version of the manuscript.

Funding. None.

Conflicts of interest. None.

1. Browne A, Williams KR. Gender, intimacy, and lethal violence: Trends from 1976 through 1987. Gender Soc 1993;7(1):78-98. https://doi.org/10.1177/089124393007001005

2. Steffensmeier D, Haynie DL. The structural sources of urban female violence in the United States: A macrosocial gender-disaggregated analysis of adult and juvenile homicide offending rates. Homicide Stud 2000;4(2):107-134. https://doi.org/10.1177/1088767900004002001
3. Suffla S, Seedat, M. Socio-demographic and spatio-temporal predictors of homicidal strangulation in the City of Johannesburg, South Africa. Afr Saf Promot J 2019;17(1):1-16

4. Kramer S, Ratele K. Young black men's risk to firearm homicide in night time Johannesburg, South Kramer S, Ratele K. Young black men's risk to firearm homicide in night time Johannesburg, South
Africa: A retrospective analysis based on the National Injury Mortality Surveillance System. Afr Saf Africa: A retrospective ana

Pridemore WA. Demographic, temporal, and spatial patterns of homicide rates in Russia. Eur Sociol Pridemore WA. Demographic, temporal, and spatial patte

Agha S. Structural correlates of female homicide: A cross-national analysis. J Crim Justice 2009;37:5766. Agha S. Structural correlates of female homicide: A cross-
585. https://doi.org/10.1016/j.jcrimjus.2009.09.006

7. Haynie DL, Armstrong DP. Race- and gender-disaggregated homicide offending rates. Homicide Stud 2006;10(1):3-32. https://doi.org/10.1177/108876790528151

8. Madkour AS, Martin SL, Halpern CT, Schoenbach VJ. Area disadvantage and intimate partner homicide: An ecological analysis of North Carolina counties, 2004 - 2006. Violence Victim 2010;39(10):1211-1225. https://doi.org/10.1891/0886-6708.25.3.363

9. Vieraitis L, Britto S, Kovandzic TV. The impact of women's status and gender inequality on female homicide victimization rates: Evidence from U.S. counties. Fem Criminol 2007;2(1):57-73. https://doi. org/10.1177/1557085106294187

0. Suffla S, Seedat, M. The epidemiology of homicidal strangulation in the City of Johannesburg, South Africa. J Forensic Leg Med 2016;37:97-107. https://doi.org/10.1016/j.jflm.2015.11.005

1. Glass N, Laughon K, Campbell J, et al. Non-fatal strangulation is an important risk factor for homicide of women. J Emerg Med 2008;35(3):329-335. https://doi.org/10.1016/j.jemermed.2007.02.065

12. Messing JT, Patch M, Wilson JS, Kelen GD, Campbell J. Differentiating among attempted, completed, and multiple nonfatal strangulation in women experiencing intimate partner violence. Womens Health Issues 2018;28(1):104-111. https://doi.org/10.1016/j.whi.2017.10.002

13. Shields LBE, Corey TS, Weakley-Jones B. Stewart D. Living victims of strangulation: A 10-year review of cases in a metropolitan community. Am J Forensic Med Path 2010;31(4):320-325. https://dol. org/10.1097/PAF.0b013e3181d3dc02

14. United Nations Office on Drugs and Crime. 2011 Global Study on Homicide: Trends, Contexts, Data Vienna: UNODC, 2011. https://www.unodc.org/documents/congress/background-information/ Crime_Statistics/Global_Study_on_Homicide_2011.pdf (accessed 12 November 2014).

15. Krienert JL, Walsh JA. Eldercide: A gendered examination of elderly homicide in the United States, 2000 - 2005. Homicide Stud 2010;14(1):52-71. https://doi.org/10.1177/1088767909352736

16. Safarik ME, Jarvis JP, Nussbaum, KE. Sexual homicide of elderly females: Linking offender characteristics to victim and crime scene attributes. J Interpers Violence 2002;17(5):500-525. https:// characteristics to victim and crime scene
doi.org $/ 10.1177 / 0886260502017005002$

17. Mathews S, Abrahams N, Jewkes R, Martin LJ, Lombard C. The epidemiology of child homicides in South Africa. Bull World Health Organ 2013;91(8):562-568. https://doi.org/10.2471/BLT.12.117036

8. Swart L, Seedat M, Nel J. The situational context of adolescent homicide victimization in Johannesburg South Africa. J Interpers Violence 2018;33(4):637-661. https://doi.org/10.1177/0886260515613342

9. Suffla S, van Niekerk A, Arendse N. Female homicidal strangulation in urban South Africa. BMC Public Health 2008;8:363. https://doi.org/10.1186/1471-2458-8-363

20. Mathews S, Abrahams N, Martin LJ, Vetten L, van der Merwe L, Jewkes R. 'Every Six Hours a Woman is Killed': A National Study of Female Homicide in South Africa. Cape Town: Medical Research Council, 2004. https://pdfs.semanticscholar.org/bb49/2eab852ff61878eb9e50113e40aff2f9e0ff.pdf (accessed 14 November 2014)

21. Salfati CG. The nature of expressiveness and instrumentality in homicide: Implications for offende profiling. Homicide Stud 2000;4(3):265-293. https://doi.org/10.1177/1088767900004003004

22. Pizarro JM. Reassessing the situational covariates of homicides: Is there a need to disaggregate? Homicide Stud 2008;12(4):323-349. https://doi.org/10.1177/1088767908323741

23. Ratele K, Swart L, Seedat M. Night-time fatal violence in South Africa. In: Hadfield P, ed. Nightlife and Crime: Social Order and Governance in International Perspective. Oxford: Oxford University Press, 2009:277-293

24. Carbone-Lopez K, Lauritsen J. Seasonal variation in violent victimization: Opportunity and the annual rhythm of the school calendar. J Quant Criminol 2013;29:399-422. https://doi.org/10.1007/s10940012-9184-8

25. Häkkänen $\mathrm{H}$. Homicide by ligature strangulation in Finland: Offence and offender characteristics. Forensic Sci Int 2005;152(1):61-64. https://doi.org/10.1016/j.forsciint.2005.02.032

26. Marvell TB, Moody CE. Female and male homicide victimization rates: Comparing trends and regressors. Criminology 1999;37(4):879-900. https://doi.org/10.1111/j.1745-9125.1999.tb00508.X

27. Miethe TD, Regoeczi WS, Drass KA. Rethinking Homicide: Exploring the Structure and Process

Underlying Deadly Situations. Cambridge: Cambridge University Press, 2004. 